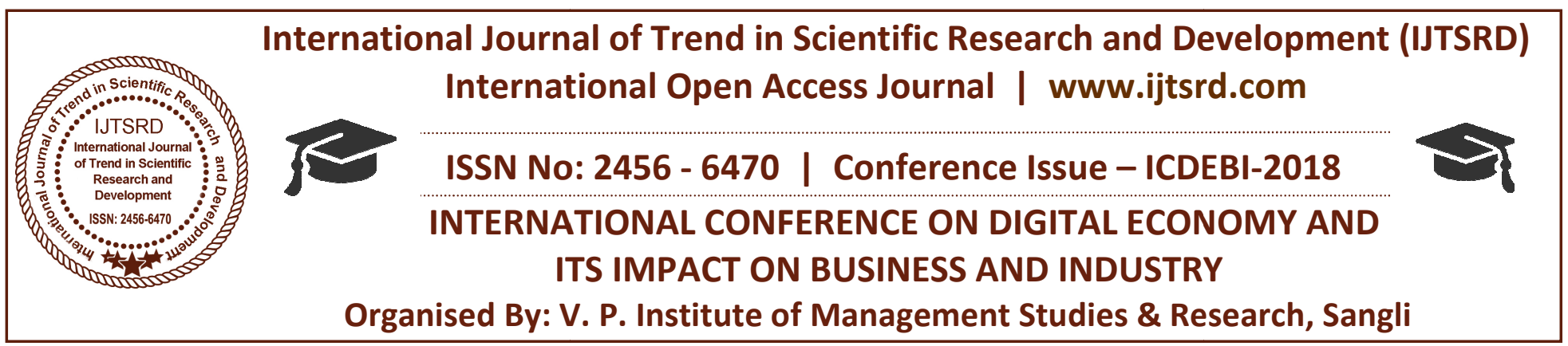

\title{
The Role of AcademicLibraries in Technical Environs for Quality Education
}

\author{
Dr. Mrs. Kulkarni A. M. \\ M.Com, M.A., M.Lib. M.Phil., Ph.D. (SET), Librarian \\ V. P. Institute of Management Studies \& Research, Sangli, Maharashtra, India \\ Affiliated to Shivaji University, Kolhapur, Maharashtra, India
}

\begin{abstract}
The explosion of information and increase in the use and craze of Internet, academic libraries has faced new challenges to look for new ways to meet the user's demands and expectations. It is essential to bring information to various users has encouraged the creation of many advanced services linking new technology with services and its day to day transactions. In the current technical environment, library professional need to redefine their role. By using of new technologies in academic library, they can give best services to library users. An academic library has to play the role as a central gateway for library users to access, to search, transform and utilize information resources in a variety of printed and electronic formats through databases, networks, applications and systems.
\end{abstract}

As our educational system is getting more and more dynamic. Hence, the academic librarians have to change themselves and try to apply new technologies in their libraries. This paper is focused on the significance and various sources of modern technology in academic libraries, which will contribute tremendous changes in services and make it easy to conduct daily routine library work and also explains the need of new technologies in academic libraries and various new technologies in academic libraries.

\section{INTRODUCTION}

In this age of information and ICT, academic libraries are required to work individually or as a team to deliver service oriented and user applications,

instructions, programs, projects and services. An academic library has to provide users with dynamic tools, facilities, resources and various services to support their learning activities which cover assignments, projects, presentations, research papers etc. An academic library shall provide best supporting and training facilities and instructors for designing, developing, integrating, and implementation of various teaching courses, programs workshops tec. In these services new technologies in academic library is very imperative for giving best services to library users.

\section{Need of Academic Library Users in Technical Era}

In last 25 years, libraries were reliant on their own resource to understand their user's information needs, but that time they have some limitations i.e. time, location, financial lacunae etc. Then came an era of computerization where libraries started working in collaborative manner being connected through networks or consortia to utilize the resources. However, with the introduction of technology, the scenario has totally changed as today they can provide information $24 \times 7$ and crossing all the geographical boundaries, this is possible because of the computers and accessing the networking and consortia in libraries. Today's users have specific information needs. Today's student's information requirements are becoming more and more personalized. Academic libraries are focusing on appropriate, timely and multilevel services for their academic users by using different service models such as WWW, File Transfer Protocol, Bulletin Board Services and email. 
'In a quickly changing educational atmosphere, academic libraries need more time and staff resources to meet the needs of faculty and students. They are also looking for tools that shine a light on their energetic contributions toward the success of their academic institutions ${ }^{\prime}$. (https://www.oclc.org/en/academic.html). The college or academic library is played significant role in this rapid altering computing period. Their role contains: classification and assortment of information, its institute of administration, storeroom recovery and distribution to correct clients at precise era at exact place at right value and in exactly arrangement.

Academic library:

'An academic library is a library that is involved to a higher education institution which assists two complementary purposes to support the school's course and to support the research of the university faculty and students, ${ }^{2}$.(Curzon, Susan)

All college libraries have improved their facilities and information resources arrangements. Now days we are living in the era of computer and information technologies which is plays extremely fundamentals responsibility in library discipline i.e. for collection, storage, organization, processing and analysis of information.

\section{New Technologies for Academic Libraries:}

There are some new technologies for academic libraries which is very useful for quality education.

\section{Computerization. :}

At the moment, everyone is going to use computers in ever-increasing information in ways never probable extremely soon little years before. The computer is a good number for helpful contemporary instrument, however developed.

\section{Digitization. :}

Library digitization is the process of utilizing computers, database, multimedia equipment, networks, video equipment and web technologies to electronically collect, classify, copy, compress, scan, store, and transform, conventional library information resources.

3. Library Automation. :

Library automation was the first step towards the procedure of new technology in academic libraries. It brings excessive revolution and save the time of users and academic staff for collecting information. Library automation mentions to use of computers, associated peripheral media such as software for automation, magnetic, tapes, disks, optical media etc.

4. ICT Technology. :

It is typically called ICT which is frequently used as a comprehensive synonym for developing teaching-learning process. Other than, it is typically a further universal word that anxiety the role of united communications and the addition of telecommunications. It also consists of all technological earnings used to grip information and support, communication, together with computer and internet, communication middleware as well as important software.

\section{Internet and Wi-Fi Technology. :}

The internet is a worldwide system of unified computer network. It uses for the standard internet protocol set to provide billions of users wide reaching. It is a network of system which consists of millions of confidential, community, educational, commerce, and administration networks of limited to worldwide range. Academic libraries are using the internet to sustain their essential purpose and services; achievement, movement, and classification and given that admission to the internet as a self-governing services.

Wi-Fi Technology is the best way for academic library to attract new generation users at library. Users need not wait for the desktop computer engaged by other users. The Wi-Fi facility enables them to access the internet using their mobile devices. Wi-Fi technologies should give the college students, a friendly environment and motivate them to come to the library. This will be enable quick access of online materials and would connect them with the other libraries.

\section{Barcode Technologies. :}

It can be clear as a self-restricted communication with information prearranged in a sequence of black blocks of unreliable breadths and colorless places between each two of them. The bars and places stand for a sequence of characters or numbers. These are legible only by a scanner which sends meaning to the computer that interpret such bars on 0's and 1's instead of characters in such as can be recognized by computer only. The barcode has a tag of book attainment of exacting library and classify the book with tag. 
7. Collection Development with $\mathbf{E}$ - Database. :

Academic libraries should develop both print and non print collection; it willhelp to students use at library. With the ever expanding technology informationis stored both print and digital formats. So, academic library should need a collection of audio and video materials and should have subscription to e-journals and e- books etc.

\section{Institutional Repositories. :}

An Institutional Repositories is an online source for collecting, preserving and disseminating information in digital form which is the intellectual output of an institution, particularly academic and research institution. I $R$ are accessible from remote places and can be downloaded by users desiring to have it, though there could be some regulations for using the institutional repositories.

9. Social Networking. :

Social networking services are an online service that focuses on building and reflecting of social networks and social relations among the people. Various social networking sites like face book, MySpace, What's app, Blogs, etc. can be used for information dissemination in academic library.

10. Library 2.0.:

The term Library 2.0, first coined by Michal Casey in on his blog Library Crunch, refers to a number of social and technological changes that are having impact upon libraries, its staff and their customers, and how they could interact. It is a model for reorganized form of library services that replicates a transition within the library world in the way services are delivered to users. Library 2.0 is a concept that personified new age group of academic library services to meet the present day user's needs and expectations. ${ }^{3}$ (https://en.wikipedia.org/wiki/Library 2.0).

\section{RFID Technology. :}

Radio frequency identification is a term used for technologies exploiting radio waves for identifying individual items automatically. The most common way is storing a serial number identifying a product (Book/Documents) and related information on a microchip attached to an antenna. RFID is one of today's most thrilling and fastest growing technologies for increasing efficiencies, improving profitability and an important area of study in today's information environment. Due to hike in prices of books and documents, it becomes very essential to secure the library collection. RFID is the most effective way for protect the collection of library.

12. Virtual Library. :

Virtual Library is the place from where access to universal knowledge on the desktop. It creates it's on outfits. The main goal is to provide virtual experience to the users due to the explosion of knowledge. Virtual library creates constant touch between the learning resources centre and the users and making the learning more interesting.

The 'give and take' system of the library must not be only to a library. $21^{\text {st }}$ century is century of knowledge, so informative library services has been very essential in this digital era.

\section{Conclusion:}

$21^{\text {st }}$ century is actually age of Information, knowledge and information Communication Technology. The role of academic library professionals has become more challenging in modern world. So, librarians keep update themselves about the new technologies and implement them effectively. Academic libraries are very important part of the academic institution. Use of technologies in the information science in term of designing and developing the information services and product that means library services has always good result. Hence, by using of new technologies in academic library, information needs of users can fulfill immediately by providing best library services to them.

\section{REFERENCE:}

1. https://www.oclc.org/en/academic.html.

2. Curzon, Susan;Jennie Quinonez-Skinner (9 September Libraries". Encyclopedia of Library and Information Sciences. doi: 10.1081/E-ELIS3120044525.

3. https://en.wikipedia.org/wiki/Library 2.0.

4. Sundareshwari, S. (2013).Role of e-resources in the engineering college libraries. International Journal of Advanced Research in computer Science and software Engineering, 3(2).

5. https://en.wikipedia.org/wiki/Radiofrequency_identification. 